\title{
Medical students' perspectives on euthanasia and physician-assisted suicide and their views on legalising these practices in South Africa
}

\author{
R K Jacobs, MB ChB; M Hendricks, BA Hons (Psych), HDE, MA (Clin Psych), LLB; MPhil (Bioethics) \\ Centre for Medical Ethics and Law, Faculty of Medicine and Health Sciences, Stellenbosch University, Cape Town, South Africa
}

Corresponding author: R K Jacobs (ryankjacobs16@gmail.com)

Background. Euthanasia/physician-assisted suicide have been a controversial and sometimes taboo topic for a long time, not only in South Africa (SA) but also internationally. A recent (SA) judicial case has seen the topic debated again. Consensus on accepting or abolishing these practices in SA has yet to be reached. All relevant role players need to be adequately engaged before policy can be informed.

Objectives. To determine the views of future doctors (medical students) regarding euthanasia and physician-assisted suicide (PAS) and to ascertain their stance on its legalisation in South Africa (SA).

Methods. A paper-based, semi-quantitative descriptive study design consisting of 16 questions, using convenience sampling of third- to fifth-year medical students at Stellenbosch University, was used.

Results. The overall response rate was $69.3 \%(N=277)$. In total, $52.7 \%$ of participants $(n=146)$ felt that the practices of euthanasia/PAS should be legalised in SA. Responses varied depending on patient morbidities. If a patient had terminal disease with intractable suffering, $41.9 \%$ of participants would terminate the patient's life upon request. A further $36.1 \%$ of participants stated that they would have no part in ending a patient's life, while $35.0 \%$ said that they would be comfortable with providing the patient with the correct means to end their life (PAS). The majority (80.1\%) of participants indicated that they would prefer a dedicated ethics committee to decide who receives euthanasia/PAS. Many factors influenced participants' responses, but differences in opinion between and within the various religious groups were particularly evident in the responses received.

Conclusions. More than half the respondents in this study were open to legalising euthanasia/PAS, substantially more than in previous studies. However, only $41.9 \%$ of respondents would consider actually performing euthanasia/PAS, for certain patients. Views of other healthcare workers as well as the public are required before policy can be informed.

S Afr Med J 2018;108(6):484-489. DOI:10.7196/SAMJ.2018.v108i6.13089

The medical practice of euthanasia and physician-assisted suicide (PAS) remains a controversial topic, not only in South Africa (SA) but throughout the world. Euthanasia and PAS are defined as two distinct means by which an end to a patient's life can be brought about. According to Materstvedt et al., ${ }^{[1]}$ euthanasia is defined as 'a doctor intentionally killing a person by the administration of drugs, at that person's voluntary and competent request'. While PAS is defined as 'a doctor intentionally helping a person commit suicide by providing drugs for self-administration, at that person's voluntary and competent request, ${ }^{[1]}$ SA law regards both euthanasia and PAS as forms of active euthanasia. ${ }^{[2]}$ The South African Law Commission ${ }^{[3]}$ holds that 'such an act [euthanasia and/or PAS] would undoubtedly be unlawful and the person giving the assistance could be convicted of murder', as both euthanasia and PAS contain the definitional elements of murder. Despite the fact that $34 \%$ of SA doctors surveyed in $2011^{[4]}$ had already had patients request life-ending interventions, it is evident that fear of prosecution contributes to doctors' reluctance to perform these procedures. Given past requests for euthanasia and PAS, the time to consider legislative change is fast approaching, and to pre-empt the legislative review it is prudent to explore the attitudes of doctors towards these life-ending practices. ${ }^{[5]}$

In the past, various cases have been brought before the SA judicial system. Two cases, S v De Bullocq ${ }^{[6]}$ and S v Hartmann, ${ }^{[7]}$ dealt with acts of active euthanasia, in which the motive for killing was to end useless existence and (intractable) suffering, respectively. In both cases it was found that the accused acted unlawfully. Judgment passed in these cases found the accused guilty of murder. However, lighter sentences (i.e. no imprisonment, the usual sentence for murder) were imposed, indicating the court's sympathy for the plight of the accused and the deceased. Most recently, SA courts had to consider a request for PAS from Advocate Stransham-Ford. In 2015, an application was brought to the North Gauteng High Court for assistance in dying (PAS), with the subsequent exoneration of the physician. ${ }^{[8]}$ The application was granted, but the applicant died just hours before the ruling was passed. ${ }^{[8]}$ The SA Supreme Court overturned the High Court's decision on appeal, but acknowledged euthanasia as 'a doctrine which may be in the womb of time, but whose birth is distant. ${ }^{[5]}$

The euthanasia discourse is re-emerging against the backdrop of an ageing population ${ }^{[9]}$ and the advancement of medical technologies that ultimately ensure longevity under dire medical circumstances, including longevity of patients with intractable mental illnesses. ${ }^{[10]}$ So far the courts have taken centre stage in the euthanasia debate, but with the recent developments, particularly in the Stransham-Ford case, the need to engage medical professionals has become urgent.

\section{Objectives}

To ascertain the views of future doctors on euthanasia and PAS in SA.

\section{Methods}

Design

A paper-based, semi-quantitative descriptive study design was used 
to assess the views of third- to fifth-year medical students at Stellenbosch University on euthanasia and PAS in SA.

\section{Ethical considerations and approval}

The study was approved by the Stellenbosch University Undergraduate Research Ethics Committee (ref. no. U16/03/004). Institutional approval was granted by the Stellenbosch University Institutional Research and Planning Division. The participant information sheet as well as a briefing from the principal investigator reiterated the voluntary and anonymous nature of participation in this study. Written informed consent was obtained, as per individual questionnaires. Question 1 sought consent in the form of a pre-flight checklist and subsequent tick-box.

\section{Sampling}

Convenience sampling was used. The principal investigator sought the views of a sample of third- to fifth-year medical students who were present in a lecture hall on the days when the data were collected. Students who were absent were excluded. Final-year medical students were excluded because they were not available. Third- to fifth-year medical students have already covered most of their theoretical modules (including an introductory or more formal bioethics module) and have been exposed to the working or clinical environment to varying degrees. They were deemed suitable candidates for this study as they (theoretically) have a better appreciation of the subject matter than their junior (first- and second-year) counterparts.

\section{The questionnaire}

A questionnaire containing 16 questions was used. Some questions used in the questionnaire were adapted from a survey conducted by Leppert et al. ${ }^{[11]}$ Three main categories of questions were used in the questionnaire. Table 1 elaborates on the specifics of each question relating to the topic. Questions 1 - 5 dealt with demographic information on the participants, namely consent, gender, ethnicity, year of study and religious affiliation. The questionnaire was piloted on 20 random third- to final-year medical students, for validation.

\section{Data collection and analysis}

The study was conducted from April 2016 to April 2017. Owing to the semi-quantitative descriptive study design, data collection and interpretation were two-fold. The quantitative data were captured and recorded in a Microsoft Excel (2016) workbook (Microsoft, USA) and subsequently analysed using descriptive statistics by means of frequency tables. Qualitative data were grouped and summarised (using thematic analysis) in a Microsoft Word (2016) document (Microsoft, USA). Each questionnaire was read and scrutinised twice by the primary investigator, to avoid missing or repeating any aspects that would skew the results.

\section{Results}

Of the 400 questionnaires that were distributed, 277 (69.3\%) were returned completed. 'Incomplete' questionnaires were not included in data analysis. Of the 277 completed questionnaires, 33 (11.9\%) were responses from third-year students while 99 (35.7\%) and 145 (52.3\%) were responses from fourth- and fifth-year students, respectively. Fig. 1 shows the religious affiliations of the respondents.

\section{Category 1 questions}

Category 1 questions explored students' attitudes towards life-ending requests and the legalisation of life-ending interventions in SA. The majority of the participants $(57.0 \%, n=158)$ believed that the patient should have the final decision in choosing to end their life, but only $47.7 \%$ ( $n=132$ ) believed that doctors should be allowed to help these patients fulfil their requests. Most participants $(52.7 \%, n=146)$ were in favour of legalising the practice of euthanasia and PAS in SA, but $63.5 \%(n=176)$ would still attempt to persuade a patient to choose a palliative treatment method instead of a life-ending intervention.

Table 1. Questionnaire category details

\begin{tabular}{|c|c|c|}
\hline Category & Question no. & Question \\
\hline \multirow[t]{5}{*}{1} & 6 & A patient should have a choice in deciding to end his/her life. \\
\hline & 7 & Doctors should be able to help patients to die if they wish to die. \\
\hline & 14 & $\begin{array}{l}\text { If somebody I know and love suffered from a life-threatening, painful illness. I would support their } \\
\text { decision to die. }\end{array}$ \\
\hline & 15 & $\begin{array}{l}\text { I would attempt to persuade the patient (seeking life-ending interventions) to opt for palliative therapy, } \\
\text { rather than life-ending interventions. }\end{array}$ \\
\hline & $16^{*}$ & I believe that euthanasia/physician-assisted suicide should be legalised in South Africa. \\
\hline \multirow[t]{4}{*}{2} & $8^{*}$ & $\begin{array}{l}\text { A patient known to have a painful, incurable disease (e.g. metastatic cancer), who is likely to die } \\
\text { from the condition, seeks life-ending intervention. Would you fulfil his/her wish to end his/her life } \\
\text { prematurely? }\end{array}$ \\
\hline & $9^{*}$ & $\begin{array}{l}\text { A patient known to have a painful, incurable disease (e.g. metastatic cancer) but who is unlikely to die } \\
\text { soon seeks life-ending intervention. Would you fulfil his/her wish to end his/her life? }\end{array}$ \\
\hline & $10^{*}$ & $\begin{array}{l}\text { A patient presents to you with no known disease, but seeks life-ending intervention. Would you fulfil } \\
\text { his/her wish to end his/her life? }\end{array}$ \\
\hline & $11^{\star}$ & $\begin{array}{l}\text { Should a patient with a known (medically resistant) psychiatric condition also be granted end-of-life } \\
\text { options - as for those with terminal medical conditions? }\end{array}$ \\
\hline \multirow[t]{2}{*}{3} & $12^{*}$ & $\begin{array}{l}\text { A patient known to have a painful, incurable disease (e.g. metastatic cancer) seeks life-ending } \\
\text { interventions. Would you be willing to be the person administering the lethal medication (active } \\
\text { euthanasia) or facilitate the process of dying by prescribing the lethal medication (physician-assisted } \\
\text { suicide)? }\end{array}$ \\
\hline & $13^{*}$ & $\begin{array}{l}\text { Regarding performing euthanasia/physician-assisted suicide (for all patients seeking it), I would prefer } \\
\text { to: }\end{array}$ \\
\hline
\end{tabular}


Variations among participants with different religious affiliations were noted. Most respondents in all the groups (52.3\% of Christians ( $n=102), 73.9 \%$ of Islamic students $(n=34), 57.1 \%$ of Hindus $(n=4)$, $87 \%$ of agnostics $(n=20)$ and $100 \%(n=6)$ of those who did not list a religious affiliation agreed that euthanasia/PAS should be legalised in SA. Higher proportions of respondents in most of these groups felt that patients should be allowed to decide if they want to end their lives prematurely, and that doctors should be allowed to assist them. However, while the majority of Islamic students $(56.5 \%, n=26)$ felt that euthanasia/PAS should be legalised in SA, the same proportion also felt that doctors should not assist patients in ending their lives prematurely. Some Islamic students $(39.1 \%, n=18)$ maintained that patients should not be allowed to decide to end their lives prematurely. In contrast, nearly half of the agnostic medical students $(43.5 \%, n=10)$, presumably with a naturalistic world view, would not attempt to persuade the patient to opt for palliative care. Fig. 2 highlights the differences in the numbers of participants who would

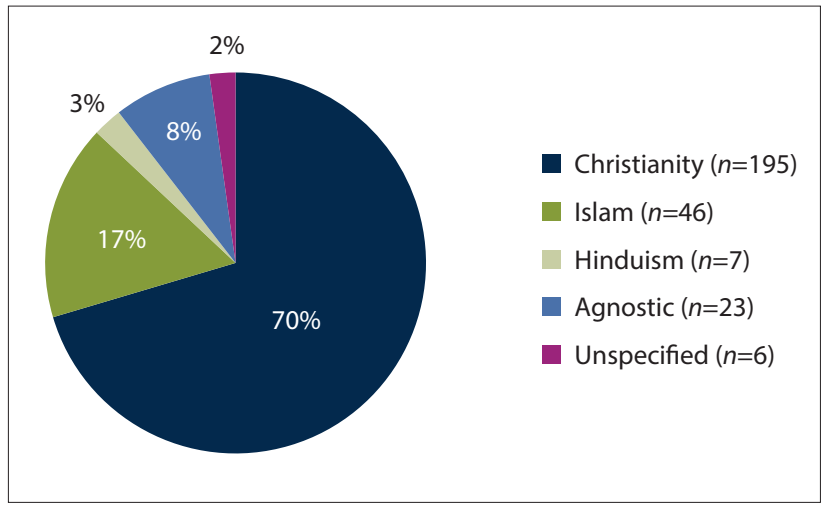

Fig. 1. Religious affiliations of respondents $(\mathrm{N}=277)$ (no respondent listed Judaism as their religious affiliation).

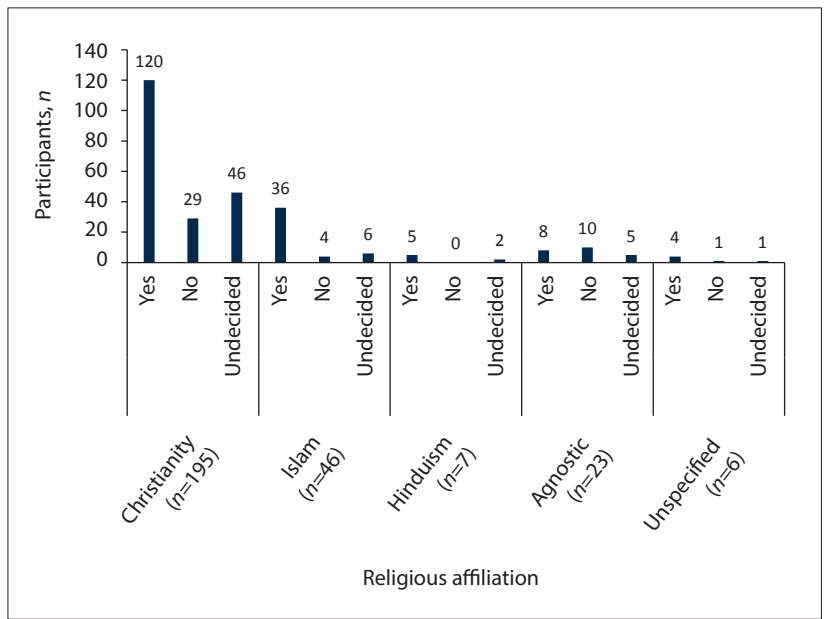

Fig. 2. Numbers of participants from the different religious affiliations who would attempt to persuade a patient to opt for palliative care $(\mathrm{N}=277)$. or would not attempt to persuade a patient to opt for palliative care, according to religious affiliation. Of the group as a whole, 50.2\% ( $n=139)$ said that they would be supportive of a loved one who wanted to end their life prematurely owing to intractable disease. Islamic students differed from their peers in this regard, with only $23.9 \%$ ( $n=11$ ) stating that they would be supportive of such a decision taken by a loved one.

\section{Arguments supporting and opposing euthanasia/PAS}

The main arguments presented by respondents in support of and opposing the legalisation of euthanasia/PAS in SA are outlined in Table 2. The results indicate that the views of these future SA doctors on this topic resonate with those of medical practitioners nationally and internationally. ${ }^{[11-17]}$ These arguments are covered in greater detail in the discussion section of this article.

\section{Category 2 questions}

These questions explored students' opinions regarding patient groups in which they would be more or less likely to perform or assist with active euthanasia or PAS. Four scenarios briefly detailing the morbidity of the patient who wished to hasten their death were presented. Results were largely unanimous across each specific question. With regard to the two questions on patients with painful, incurable disease, where the scenarios were similar but with a minor difference relating to duration of life remaining, responses were significantly different, $41.9 \%(n=116)$ of participants stating that they would assist in hastening death in a terminally ill patient with intractable suffering who was unlikely to live for much longer, but $71.1 \%(n=197)$ indicating that they would not hasten the death of a patient with the same morbidity (terminally ill with intractable suffering) if the patient had a longer time to live - although no exact time frame was provided. Nearly all the students (90.6\%) $(n=251)$ said that they would not assist a patient with life-ending interventions if the patient had no known treatable medical illness, and $54.2 \%$ $(n=150)$ said that they would not assist a psychiatric patient to end their life prematurely. Participants of Islamic religious affiliation were largely opposed to assisting patients in hastening their death in any of the above scenarios. Reasons provided by respondents regarding which patients they would or would not consider assisting with euthanasia/PAS are set out in Table 3.

\section{Category 3 questions}

These questions explored students' preferences for consultation regarding decision-making for patients requesting life-ending interventions. The majority of participants $(80.1 \%, n=222)$ indicated that they would prefer to have a dedicated ethics team decide on which patient is eligible for euthanasia/PAS. Only $10.1 \%(n=28)$ of the respondents said that they would prefer to refer the patient, and the remaining $9.8 \%(n=27)$ indicated that they would choose either to decide for themselves or to consult a colleague. Responses to the question relating to who should decide if a patient should be granted their wish to hasten their death are outlined in Table 4.

Table 2. Main arguments of medical students with regard to legalising euthanasia/physician-assisted suicide

In support
Patient autonomy
Relief of suffering
In opposition
Doctor's oath to preserve life
Morally wrong - against personal/religious world view
'Slippery slope' towards active involuntary euthanasia


autonomy. The word autonomy, deriving from the Greek auto (self) and nomos (rule), refers to a person's ability to make independent choices about his/her life. Autonomous, competent individuals have a fundamental right to decide what they deem to be good and necessary for themselves after reviewing all their options, with specific reference to healthcare and, by extension, life. ${ }^{[18-20]}$ In SA, a patient's autonomy is recognised as part of their inalienable constitutional rights, as expressed in the Constitution of South Africa ${ }^{[21]}$ and the National Health Act. ${ }^{[22]}$ Proponents of patient autonomy argue that the right to decide when one dies is or should be included in the understanding of this legislation. Internationally, patient autonomy and the significance thereof with regard to terminal illness and the wish for euthanasia/PAS are recognised and comprehensively detailed in the World Medical Association Declaration of Venice on Terminal Illness. ${ }^{[23]}$

A second argument used in support of euthanasia/PAS is that of the prevention of or relief from intractable suffering, related to the autonomous person's right to a dignified life and death. ${ }^{[19]}$ The right to dignity is acknowledged in and one of the founding values in the Constitution (section 10). ${ }^{[21]}$ Furthermore, it is widely held that no one should have to be constrained by or live with extreme suffering, if it is believed that the only way in which the suffering can be relieved is through death. ${ }^{[19]}$ Offering the patient the option of euthanasia or PAS could therefore be seen as allowing the patient to die with dignity. ${ }^{[20]}$

\section{Arguments opposing legalisation of euthanasia/PAS}

Arguments opposing the legalisation of euthanasia/PAS by students in this study concur with international data. Euthanasia/PAS are considered wrong on the basis of personal and religious morality and on the basis of the universally acceptable principles of biomedical ethics. The biomedical ethics principles of beneficence (to act in the best interests of your patient) and non-maleficence (to ensure that no harm befalls your patient following your actions) are often used as arguments opposing the legalisation of euthanasia/PAS. The merits of these principles, when viewed (by some) in isolation, seem strong enough to oppose the legalisation of euthanasia/PAS.

Additionally, the 'slippery slope' argument presented by respondents in this study follows international trends opposing euthanasia. The slippery slope argument infers that the consequences of certain actions (such as legalising euthanasia and/or PAS) may, on their own, be worse than the actual anticipated consequences of prohibiting the said action. ${ }^{[24]}$ The single most widely used slippery slope argument states that by legalising (active) euthanasia and/or PAS, one is at direct risk of pushing the society concerned down a slope that would ultimately resemble that of Nazi Germany. ${ }^{[25]}$ The Nazi Germany analogy aims to accentuate the point that those who practise euthanasia and/or PAS may become 'dehumanised', resulting in non-beneficent killing.

\section{What type of patient would medical students assist with euthanasia or PAS?}

The majority of the participants in this study were opposed to assisting patients with no known medical condition and those with psychiatric conditions to hasten their death. Most participants expressed the view that they would be more likely to assist a patient with a known terminal illness and intractable suffering with a poorer prognosis, compared with patients with the same morbidity but a better prognosis (i.e. a longer remaining duration of life). This finding concurs with the earlier SA study, ${ }^{[4]}$ in which respondents indicated that they would not consider PAS/euthanasia for a patient without a terminal illness.
The seemingly high percentage of respondents who exhibited reluctance to assist with life-ending interventions to patients with intractable psychiatric illness raises questions regarding the teaching medical students receive on treating intractable psychiatric illnesses: namely, would these (and future) students be more liberal in their opinions about euthanasia/PAS for patients with intractable psychiatric illness if they better understood the concept of futility of treatment in psychiatry, thereby aligning their views with those held internationally - where there is an increase in support and lobbying for these life-ending interventions, as seen in the mental health literature. ${ }^{[10,26]}$

\section{How would students choose to participate in euthanasia/PAS?}

The proportion of participants who indicated that they would participate in either euthanasia or PAS differed from the earlier SA study, ${ }^{[4]}$ in that participants in the current study were more willing to perform euthanasia/PAS.

\section{Conclusions}

This study explored medical students' attitudes towards euthanasia and PAS and the prospects of legalising these practices in SA. In light of the renewed interest in the debate and the changing legal landscape, it was considered important to ascertain the views and opinions of these future doctors with regard to euthanasia and PAS, as it is believed that their views may determine their behaviour towards patients and peers. ${ }^{[12]}$ Furthermore, should euthanasia/PAS be legalised, these young doctors, even though they are not obliged to implement the policies, would potentially need to perform or assist in these procedures and practices. ${ }^{[5]}$

From this study it is evident that there is a difference in attitude towards the practice and legalisation of euthanasia/PAS between future SA doctors and present doctors (i.e. those who participated in the 2011 study). While concerns regarding the legalisation of euthanasia/ PAS do exist (for the reasons given above), if the information provided by this study holds true for medical practitioners, it is safe to accept that SA will not proceed down the slippery slope, as the majority of respondents demonstrated that they are fairly discriminatory about who to perform these life-ending interventions for. Additionally, safeguards such as developing a dedicated ethics committee to rule on case-specific applications, as well as adhering to the safeguards already outlined in the South African Law Commission's report, ${ }^{[3]}$ would further prevent the 'misuse' of these practices in SA. However, since SA is a democratic country, the views of the public should also be considered before moving to legalise or completely abolish these practices - as the SA Constitution regards individualism as equivalent to communitarianism. ${ }^{[27]}$

\section{Recommendation}

Although the responses garnered were largely unanimous across all questions, variations exist between respondents from different religious groups. These differences within as well as between various religious groups should be considered when discussing life-ending matters. These differences in opinion should be explored further in future research relating to euthanasia/PAS, as religion and culture have a significant influence on individuals' opinions and responses. ${ }^{[28,29]}$

Acknowledgements. The authors express their heartfelt gratitude to Prof. Keymanthri Moodley, Professor and Director, Centre for Medical Ethics and Law, Department of Medicine, Faculty of Health Sciences, 
Stellenbosch University, for her constant and continuous support in this research project and for assisting in obtaining both institutional and ethics approval. This article would not have been possible without her invaluable support and input.

Author contributions. RKJ: principal investigator; study conception and design; data acquisition, analysis and interpretation; article drafting. MH: supervisor; study conception and design; article revision and final approval.

\section{Funding. None.}

Conflicts of interest. None.

1. Materstvedt LJ, Clark D, Ellershaw J, et al. Euthanasia and physician-assisted suicide: A view from an EAPC Ethics Talk Force. Palliat Med 2003;17(2):97-101. https://doi.org/10.1191/0269216303pm673oa

2. Scott H. Assisted suicide and the South African constitutional order. Responsa Meridiana 1998;1-17.

3. South African Law Commission. Euthanasia and the artificial preservation of life. Paper 71 Project 86, South African Law Commission. Euthanasia and the artificial preservation of life. Paper
1997. www.justice.gov.za/salrc/dpapers/dp71_prj86_1997.pdf (accessed 5 May 2015).

1997. www.justice.gov.za/salrc/dpapers/dp71_prj86_1997.pdf (accessed 5 May 2015).
4. Ethics Institute of South Africa. Survey of Doctors Attitudes to Assisted Dying. Johannesburg: Ethics 4. Ethics Institute of South Africa.
Institute of South Africa, 2011.

5. Stransham-Ford v the Minister of Justice and Correctional Services and Others 30 April 2015, Case no. 27401/15 (NGHC).

6. S v De Bellocq 1975 (3) SA 538 (T).

7. S v Hartmann 1975 (3) SA 532 (C).

8. Minister of Justice and Correctional Services v Estate Stransham-Ford (531/2015) 2016 ZASCA 197 (6 December 2016).

9. Bongaarts J, Feeney G. How long will we live? Popul Dev Rev 2006;32(4):605-628. https://doi org/10.1111/j.1728-4457.2002.00013.x

10. Pienaar W. Developing the language of futility in psychiatry with care. S Afr J Psychiatry 2016;22(1):a978 https://doi.org/10.4102/sajpsychiatry.v22i1.978

11. Leppert W, Majkowicz M, Forycka M. Attitudes of Polish physicians and medical students toward breaking bad news, euthanasia and morphine administration in cancer patients. J Cancer Educ breaking bad news, euthanasia and morphine administration in

12. Ahmed AM, Kheir MM. Attitudes towards euthanasia among final-year Khartoum University medical Ahmed AM, Kheir MM. Attitudes towards euthanasia among final-year Khartoum University medical
students. East Mediterr Health J 2006;12(3/4):391-397. http://www.who.int/iris/handle/10665/117098 (accessed 5 May 2015).
13. Karlsson M, Strang P, Milberg A. Attitudes toward euthanasia among Swedish medical students. Palliat Med 2007;21(7):615-622. https://doi.org/10.1177/0269216307081940

14. Clemens KE, Klein E, Jaspers B. Attitudes toward active euthanasia among medical students at two Gemens KE, Klein E, Jaspers B. Attitudes toward active euthanasia among medical students at two
German universities. Support Care Cancer 2007;16(6):539-545. https://doi.org/10.1007/s00520-008German

15. Seale C. Legalisation of euthanasia or physician-assisted suicide: Survey of doctors' attitudes. Palliat Med 2009;23(3):205-212. https://doi.org/10.1177/0269216308102041

16. Leppert W, Gottwald L, Majkowicz M, et al. A comparison of attitudes toward euthanasia among medical students at two Polish universities. J Cancer Educ 2013;28(2):384-391. https://doi.org/10.1007/ s13187-012-0414-4

17. Zenz J, Tryba M, Zenz M. Palliative care professionals' willingness to perform euthanasia or physician assisted suicide. BMC Palliat Care 2015;14(1):60. https://doi.org/10.1186/s12904-015-0058-3

18. McQuoid-Mason DJ. Stransham-Ford v. Minister of Justice and Correctional Services and Others: Can active voluntary euthanasia and doctor-assisted suicide be legally justified and are they consistent with the biomedical ethical principles? Some suggested guidelines for doctors to consider. South Afr J Bioethics Law 2015;8(2):34-40. https://doi.org/10.7196/SAJBL.446

19. Landman WA. The ethics of physician-assisted suicide and euthanasia. S Afr Med J 1997;87(7):866869.

20. Egan A. Should the state support the 'right to die'? South Afr J Bioethics Law 2008;1(2):47-52.

21. South Africa. Constitution of the Republic of South Africa. Pretoria: Government Gazette, 1996.

22. South Africa. National Health Act No. 61 of 2003.

23. World Medical Association. Declaration of Venice on Terminal Illness. World Medical Association, 2006. https://www.wma.net/policies-post/wma-declaration-of-venice-on-terminal-illness/ (accessed 7 May 2015).

24. Burgess JA. The great slippery-slope argument. J Med Ethics 1993;19(3):169-174. https://doi. org/10.1136/medethics-2012-100678

25. Lamb D. The slippery slope argument. In: Lamb D, ed. Down the Slippery Slope: Arguing in Applied Ethics. London: Croom Helm, 1988

26. Berghmans R, Widdershoven G, Widdershoven-Heerding I. Physician-assisted suicide in psychiatry and loss of hope. Int J Law Psychiatry 2013;36(5-6):436-443. https://doi.org/10.1016/j.ijlp.2013.06.020

27. Wing AK. Communitarianism vs. individualism: Constitutionalism in Namibia and South Africa. Wisconsin Int Law J 1992:295(11):295-380, http://iruiowa edu/law pubs/1495 (accessed 12 May 2015)

28. Bullock K. The influence of culture on end-of-life decision making. J Soc Work End Life Palliat Care 2011;7(1):83-98. https:// doi.org/10.1080/15524256.2011.548048

29. Gielen J, van den Branden S, Broeckaert B. Religion and nurses' attitudes to euthanasia and physician assisted suicide. Nurs Ethics 2009;16(3):303-318. https://doi.org/10.1177/0969733009102692

Accepted 1 February 2018. 